\title{
Growing Teratoma Syndrome: An Enigma
}

\author{
${ }^{1}$ Latika Chawla, ${ }^{2}$ Lalit Kumar, ${ }^{3}$ Sandeep Mathur, ${ }^{4}$ Sunesh Kumar
}

\begin{abstract}
The phenomenon of growing teratoma syndrome (GTS) is a curious entity well recognized in testicular nonseminomatous germ cell tumors (NSGCT), but rare in ovarian immature teratomas. It involves the conversion of immature to mature components during or after chemotherapy with further growth in the size of the lesions but containing only mature elements on histopathology, which could be clinically confused with malignant recurrence. Treatment involves complete surgical excision. Prognosis is usually favorable if the disease if completely resected, however mortalities even though rare have been reported. We herein describe two rare cases, with clinical features, diagnosis, complications, and management of the condition.
\end{abstract}

Keywords: Conversion, Immature teratoma, Ovarian mature teratoma.

How to cite this article: Chawla L, Kumar L, Mathur S, Kumar S. Growing Teratoma Syndrome: An Enigma. J South Asian Feder Obst Gynae 2018;10(Suppl 1):355-357.

\section{Source of support: Nil}

Conflict of interest: None

Date of received: 16 April 2015

Date of acceptance: 15 february 2018

Date of publication: July 2019

\section{INTRODUCTION}

The growing teratoma syndrome (GTS) is a peculiar occurrence involving conversion of immature gonadal germ cell tumor components to mature components, during/after chemotherapy along with increase in size of the tumor mass, normal tumor markers and histopathology demonstrating only mature components This is a well-recognized entity in non-seminomatous germ cell tumor of the testis with an incidence of $1.9-7.6 \% .{ }^{1}$ With

\footnotetext{
${ }^{1}$ Senior Resident, ${ }^{2,4}$ Professor, ${ }^{3}$ Associate Professor

${ }^{1,4}$ Department of Obstetrics and Gynecology, All India Institutes of Medical Sciences, New Delhi, India

${ }^{2}$ Department of Medical Oncology, All India Institute of Medical Sciences, New Delhi, India

${ }^{3}$ Department of Pathology, All India Institute of Medical Sciences, New Delhi, India

Corresponding Author: Latika Chawla, Senior Resident, Department of Obstetrics and Gynecology, All India Institute of Medical Sciences, New Delhi, India, e-mail: latika.c@rediffmail. com
}

just 22 case reports in literature so far, the incidence of this conversion in ovarian teratomas is not known.

\section{CASE DISCRIPTION}

\section{Case 1}

A 23-year-old female underwent surgery in March 2013 for an immature teratoma, Norris grade II. (CA 125 was $521 \mathrm{U} / \mathrm{mL}$, alpha fetoprotein was $98.77 \mathrm{ng} / \mathrm{mL}$ ). She received four cycles of chemotherapy with bleomycin, etoposide, and cisplatin (BEP). Follow-up PET scan after 2 months showed a $6.5 \times 6 \mathrm{~cm}$ mass in the pouch of Douglas (POD) with calcifications and avid FDG uptake (Fig. 1). Tumor markers remained normal. Repeat PET scan after 4 months showed an increase in the size of the tumor with the development of more calcification, fatty attenuation, necrotic areas, but a decrease in the metabolic activity. The patient subsequently developed obstructive urinary symptoms, thus was taken up for surgery. Intraoperatively a $17 \times 10 \mathrm{~cm}$ solid mass was adhered to the postsurface of the uterus and sigmoid which on the cut surface showed hair, cartilage, fatty and sebaceous material (Fig. 2). Histopathology revealed a mature teratoma. The patient is currently healthy and on follow-up with us.

\section{Case 2}

A 29-year female, known case of growing teratoma syndrome had undergone a staging laparotomy for an immature teratoma in 2003, followed by four cycles of chemotherapy with BEP. In 2008, she had a second surgery, with the removal of a $10 \times 10 \mathrm{~cm}$ solid mass from the POD, and tumor mass excision from the undersurface of diaphragm. Histopathology showed a mature cystic teratoma. The third laparotomy was done in 2011 with the removal of $6 \times 8 \mathrm{~cm}$ a tumor mass from POD. Histopathology again revealed a mature cystic teratoma. This time CECT showed an $18 \times 16 \mathrm{~cm}$ mass, with internal calcification and necrosis, which had markedly increased in size as compared to the previous follow-up scans. Intraoperatively, the large solid cystic mass with densely adhered to the small bowel, colon, and omentum. She underwent pelvic tumor excision with distal colon rent repair with a loop ileostomy. Postoperative course was hectic. The patient developed sepsis and finally succumbed to the disease due to pulmonary embolism. Histopathology showed stratified squamous epithelium, keratin, adnexal structures, cartilage, adipose tissue, bone, 

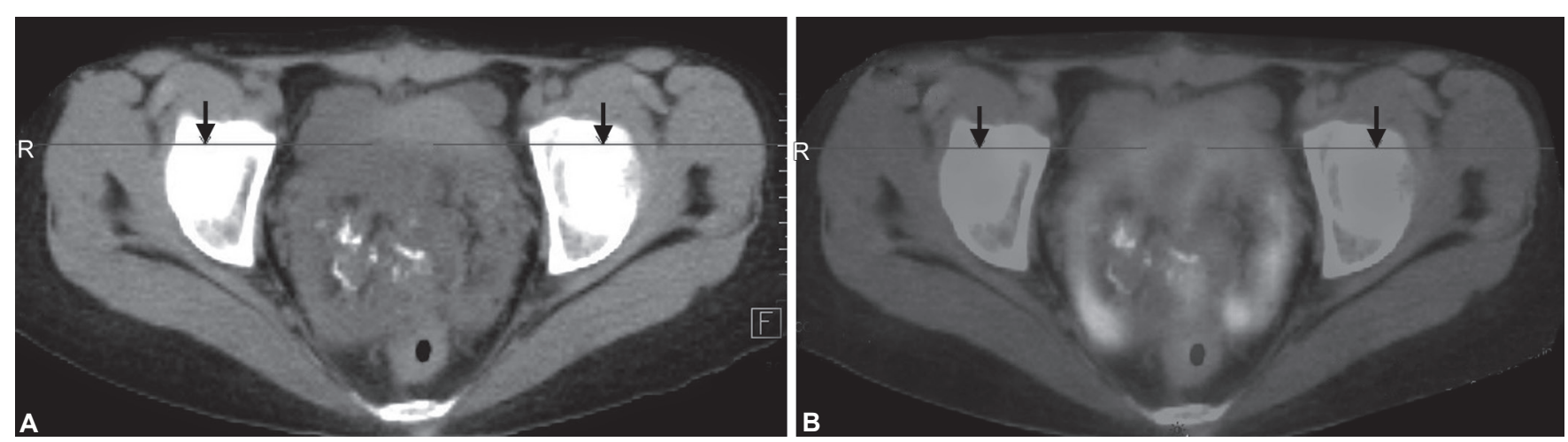

Figs 1A and B: Postoperative PET scan showing a mass in the POD with avid FDG uptake, areas of calcification and fatty change

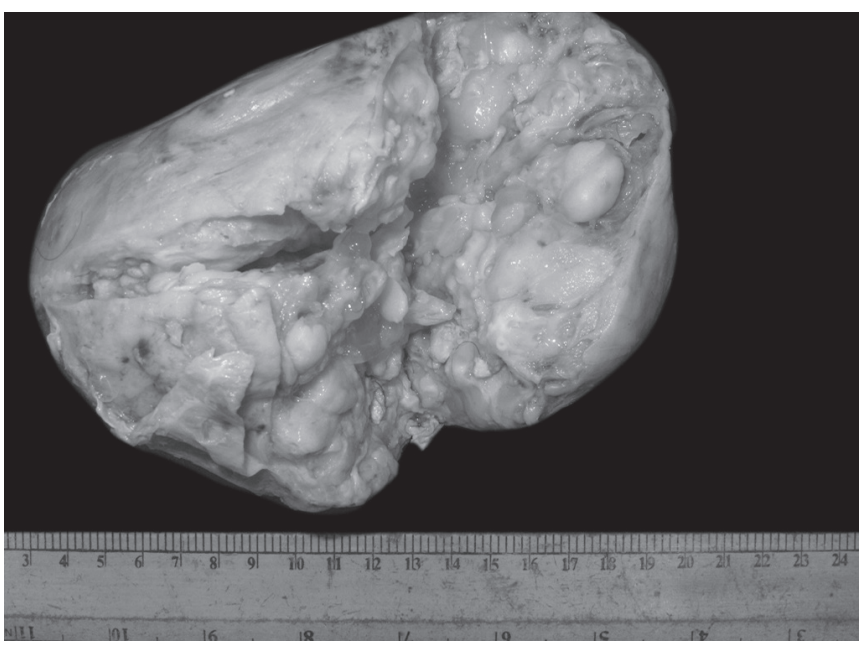

Fig. 2: Mature teratoma removed from the pouch of Douglas

glial and immature neuroepithelial elements, suggestive of immature teratoma Norris grade II.

\section{DISCUSSION}

Various hypothesis for the GTS have been proposed:

- Chemotherapy-induced conversion of malignant to benign cells

- Natural selection of benign cells, with chemotherapyinduced destruction of malignant cells

- Spontaneous transformation of malignant germ cell into benign tissues. ${ }^{2}$

The patients may present with a mass in the pelvis/ abdomen or, the disease may be picked up on follow-up scans. ${ }^{3}$ The tumor masses may grow rapidly/remain stable for years together. The behavior remains unpredictable. $^{4}$

CT findings like an increase in density of the lesion, presence of fatty areas, cystic changes and internal calcification may suggest the presence of mature elements, thus help in diagnosis..$^{5}$ Absence of activity on PET scan has been considered to be diagnostic of mature neoplasm, ${ }^{6}$ although other studies report positive uptake $\mathrm{e}^{7}$ like in our first patient, thus limiting the utility of this modality for diagnosis.
Malignant transformation is a rare complication with an incidence of $3 \% .^{7}$ Our second patient after a follow-up of 11 years and 4 laparotomies, developed malignant transformation, which is a rare event worth reporting. The mature teratomas might transform into immature teratoma, sarcoma, squamous cell carcinoma, adenocarcinoma, carcinoids or primitive neuroectodermal tumors. ${ }^{7}$

These tumors are refractory to chemotherapy, and as patients are at risk of obstructive complications due to the growing tumor mass, optimal cytoreduction is the treatment of choice. Referral to specialized gyne-oncological units, and follow up imaging is important because recurrences are common in the first 10 years.

If the patient has been operated multiple times for recurrences or surgery carries significant risk or if the tumor seems unresectable, medical management with agents like interferon alpha, bevacizumab can be considered. $^{8}$

Prognosis is usually favorable considering the benign nature of the disease; however, mortalities like in our second patient have rarely been reported in the literature. Removal of the complete tumor load at the first surgical endeavor would minimize recurrences and improve the prognosis. Our first patient was a classic representation of the GTS. The second patient showed us that the disease in its natural course could have multiple recurrences, necessitating multiple explorations.

\section{REFERENCES}

1. Logothetis CJ, Samuels ML, et al. The growing teratoma syndrome. Cancer 1982;50:1629-1635.

2. Gorbatiy V, Spiess PE, et al. The growing teratoma syndrome: Current review of the literature. Indian J Urol 2009; 25:186-189.

3. Andre F, Fizazi $\mathrm{K}$ et al. The growing teratoma syndrome: results of therapy and long-term follow-up of 33 patients. Eur J Cancer 2000;36:1389-1394.

4. Byrd K, Stany M et al. Growing teratoma syndrome: Brief communication and algorithm for management. ANZJOG 2013;53:318-321. 
5. Moskovic E, Jobling T, et al. Retroconversion of immature teratoma of the ovary: CT appearances. Clin Radiol 1991;43:402-408.

6. Kikawa S, Todo Y, et al. Growing teratoma syndrome of the ovary: a case report with FDG-PET findings. J Obstet Gynaecol Res 2011;37:926-932.
7. Aide N, Comoz F, et al. Enlarging residual mass after treatment of a nonseminomatous germ cell tumor: growing teratoma syndrome or cancer recurrence? J Clin Oncol 2011;25:4494-4496.

8. Mego M, Reckova M, et al. Bevacizumab in a growing teratoma syndrome. Case report. Ann Oncol 2007;18:962-963. 